\title{
The Superficial Inferior Epigastric Artery Fascia Flap in Rats
}

\author{
Tiam M. Saffari, MD ${ }^{1,2}$ Allen T. Bishop, MD ${ }^{1} \quad$ Alexander Y. Shin, MD ${ }^{1}$ \\ ${ }^{1}$ Division of Hand Surgery, Department of Orthopedic Surgery, Mayo \\ Clinic, Rochester, Minnesota, United States \\ 2 Department of Plastic-, Reconstructive- and Hand Surgery, Erasmus \\ Address for correspondence Alexander Y. Shin, MD, Division of Hand \\ Surgery, Department of Orthopedic Surgery, Mayo Clinic, 200 1st St. \\ SW, Rochester, MN 55905 (e-mail: shin.alexander@mayo.edu).
} Medical Center, Rotterdam, The Netherlands

J Reconstr Microsurg Open 2020;5:e7-e14.

\begin{abstract}
Background An adipofascial flap in the rat may provide new options for adding vascularization to scarred or nonvascularized beds for a variety of research studies. Current literature lacks sufficient description for a simple reproducible flap model for a vascularized pedicled flap in rats, in particular for neovascularization of allograft nerves for the reconstruction of sciatic nerve defects. The purpose of this study was to describe a surgical technique and determine long-term survivability for the pedicled superficial inferior epigastric artery fascial (SIEF) flap in the rat to meet requirement for a tunneled adipofascial flap to add vascularization to the sciatic nerve area.

Methods The technique and use of a $4 \times 3-\mathrm{cm}$ SIEF flap are described. Twenty Lewis rats underwent the technique to determine feasibility. The flap was wrapped around processed allograft nerve reconstructions and viability of the flap was evaluated after 12 and 16 weeks. To visualize vessels, nerve grafts were harvested at 12 weeks and stained with hematoxylin-eosin and an antibody against microvessels (CD-34).

Results All flaps remained viable after survival of 12 and 16 weeks. Complications included one hematoma formation and two lymphocele formations that did not have any impact on the flap. Immunohistochemistry confirmed an increase in microvessels

Keywords

- sciatic nerve vascularization

- vascularized bed

- pedicled flap

- animal models and Schwann cell nuclei in the SIEF group compared with nerve samples from the unoperated, contralateral side.

Conclusion A pedicled adipofascial flap model in the rat to provide a vascular bed for sciatic nerve reconstruction is detailed with long-term survivability evaluation of the flap. This flap is technically simple to be harvested and is suitable for revascularization procedures of various tissues in the lower abdomen, genital area, thigh, or upper limb of the rat.
\end{abstract}

It has been postulated that the application of either vascularized nerve grafts or a vascularized flap wrapped around the nerve graft will improve outcomes of nerve grafts in severely scarred tissue beds. ${ }^{1-6}$ A well-vascularized bed becomes more critical as length and caliber of a nerve graft increase. ${ }^{6}$ The literature regarding pedicled fascial flaps in animals is scarce. The free superficial inferior epigastric artery (SIEA) flap in rats was first described in 1967 by Strauch and Murray. ${ }^{7}$ This free tissue transfer could be designed in various sizes and has been applied in different investigational and training models (e.g., distal flap necrosis, ${ }^{8-12}$ ischemia reperfusion injury, ${ }^{13-16}$ and microvascular training ${ }^{17}$ ). In the rat, no previously described facial flaps have been described or used to wrap around the sciatic nerve. ${ }^{18,19}$ One study had been performed elevating a SIEA flap and evaluated for short-term viability after 7 days. ${ }^{19}$ While this pedicled flap was demonstrated to be safe and avoided the potential risk of free flap failure (microvascular anastomosis complications), long-term viability was never received

July 19, 2019

accepted after revision

December 2, 2019
DOI https://doi.org/

10.1055/s-0040-1701201. ISSN 2377-0813.
Copyright $\odot 2020$ by Thieme Medical Publishers, Inc., 333 Seventh Avenue, New York, NY 10001, USA. Tel: +1(212) 760-0888.
License terms

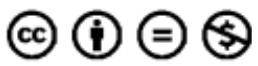


assessed. ${ }^{19,20}$ Another study described pedicled flaps to vascularize nerve grafts in an intratemporal facial nerve defect model and focused on histological outcomes. ${ }^{18}$ The sciatic nerve defect model is a well-established model to investigate multiple outcomes varying from functional motor outcomes to histology. ${ }^{21-23}$ A pedicled flap model in rats to provide vascularization to the nerve wound bed has not been described and requires validation prior to measurement of other outcomes. Therefore, the purpose of this study was to describe a reproducible surgical technique and determine long-term survivability for the pedicled superficial inferior epigastric artery fascial (SIEF) flap in the rat to meet requirement for a tunneled adipofascial flap to add vascularization to the sciatic nerve bed.

\section{Methods}

\section{Animals}

The study was approved by our Institutional Animal Care and Use Committee (IACUC A3348-18). Twenty male adult Lewis rats, weighing 250 to $300 \mathrm{~g}$ (Envigo; Madison, WI) had a unilateral $10-\mathrm{mm}$ sciatic nerve gap repaired with an optimized processed allograft (OPA). ${ }^{24}$ Ten Sprague-Dawley rats (Envigo; Madison, WI) weighing 250 to $300 \mathrm{~g}$ served as major histocompatibility mismatch donors. ${ }^{25,26}$ A $15-\mathrm{mm}$ segment of the sciatic nerve was harvested bilaterally. The nerves were cleaned from external debris and decellularized using a 5-day previously described decellularization protocol. ${ }^{24}$ The nerves were sterilized using $\gamma$-irradiation and stored in a sodium phosphate buffer (PBS) at $4^{\circ} \mathrm{C}$ until surgery. During the survival period, the Lewis rats were housed individually with a 12-hour light-dark cycle and ad libitum access to food and water. Flap viability was evaluated after $12(n=10)$ and 16 weeks $(n=10)$.

\section{Anesthesia}

Rats were anesthetized in an isoflurane chamber, shaved, prepped, and positioned in the nosecone to maintain anesthesia throughout the procedure. Body temperature was maintained at $37^{\circ} \mathrm{C}$ with a heating pad. Preoperatively, the following were administered subcutaneously; $5 \mathrm{~mL}$ of $\mathrm{NaCl}$ $0.9 \%$ to prevent dehydration, buprenorphine SR (Buprenorphine SR-LABORATORY, ZooPharm pharmacy, $0.6 \mathrm{mg} / \mathrm{kg}$ ) for pain control and enrofloxacin (Baytril; Bayer, Germany, $10 \mathrm{mg} / \mathrm{kg}$ ) providing infection prophylaxis. Postoperatively, the rats were kept warm in towels. Rats were observed daily until completion of the experiment. During sacrifice, rats were euthanized with $1 \mathrm{~mL}$ intraperitoneal injection of pentobarbital sodium (Fatal Plus; $390 \mathrm{mg} / \mathrm{mL}$, Vortech, Dearborn, MI).

\section{Surgical Procedure}

The SIEF flap is a pedicled flap supplied by superficial inferior epigastric (SIE) vessels including both the arteries and the accompanying veins. These vessels arise from femoral vessels close to branches of the popliteal and saphenous vessels, and are direct branches of the cutaneous arteries and veins. The main trunk of the SIE vessels divides into two branches. The main, lateral trunk branches from the femoral vessels in the groin and enters the abdominal wall skin. The smaller medial branch extends toward the medical abdominal skin to collateralize with a branch in the internal mammary vessel ${ }^{27}$ (-Fig. 1).

The SIEF flap measured $4 \times 3 \mathrm{~cm}$ and was designed in the ventral abdomen. After a 4-cm paramedian incision, on the ipsilateral side of the nerve reconstruction, the femoral artery was identified in the groin (-Fig. 2 ).

The SIE lateral vessels were exposed proximally and protected with a vessel loop. The flap was dissected distally, starting on the medial side. The superficial- and deep membranous layers of subcutaneous tissue (Camper fascia and Scarpa fascia) were separated from the abdominal muscles, leaving the fascia intact. Using microsurgical scissors, the flap was raised toward the proximal branch of the SIE vessels (-Fig. 3).

This dissection was performed under surgical loupe magnification to avoid damage to the SIE vessels. While dissecting, lymph nodes in the inguinal area were seen and preserved. Small vessel branches were anticoagulated using a bipolar as needed to prevent postoperative hematomas. The epigastric nerve was consistently encountered running in conjunction with the SIE vessels and transected in all cases. The flap was raised to the level of the bifurcation of the femoral artery and then kept moist in gauze until the nerve reconstruction was finished.

The sciatic nerve was fully exposed proximally from the inferior margin of the piriformis muscle to approximately $5 \mathrm{~mm}$ distal to the bifurcation under an operating microscope (Zeiss OpMi 6, Carl Zeiss Surgica, Oberkochen, Germany). A 10-mm segment of the sciatic nerve was excised by sharp transection with microsurgical scissors and bridged with a 10-mm OPA with six 10-0 nylon (10-0 Ethilon; Ethicon Inc., Sommerville, NJ), epineural interrupted sutures on either side of anastomosis.

A 2-cm linear incision was made from the patella toward the pelvis to develop a wide subcutaneous tunnel from the distal aspect of the nerve reconstruction toward the femoral artery. A hemostat was passed through the distal incision into the inguinal region, and the flap was delivered through the tunnel, with approximate 100 degrees rotation clockwise about its original axis (-Fig. 4). Caution was taken to prevent vascular twisting. The $4 \times 3$-cm SIEF flap contained subcutaneous fat, inguinal fat, femoral vasculature and SIE vessels, and was tunneled subcutaneously toward the nerve reconstruction without torsion of the pedicle (-Fig. 5A).

The flap was wrapped around the nerve allograft with the SIE vessels in line with the nerve and reaching both the proximal and distal anastomoses, as shown in - Fig. 5B. The flap edges were trimmed to fit the defect ( $\mathbf{F i g} \mathbf{~} \mathbf{5 C}$ ). Care was taken to ensure that there was no tension on the nerve anastomoses while positioning the flap under the reconstructed nerve. After ensuring that there was no pedicle compression in the subcutaneous tunnel, the vascular pedicle remained freely mobile with full ranging of the leg and that the nerve anastomoses were without tension, two loosely tied 10-0 nylon sutures (10-0 Ethilon, Ethicon Inc., 


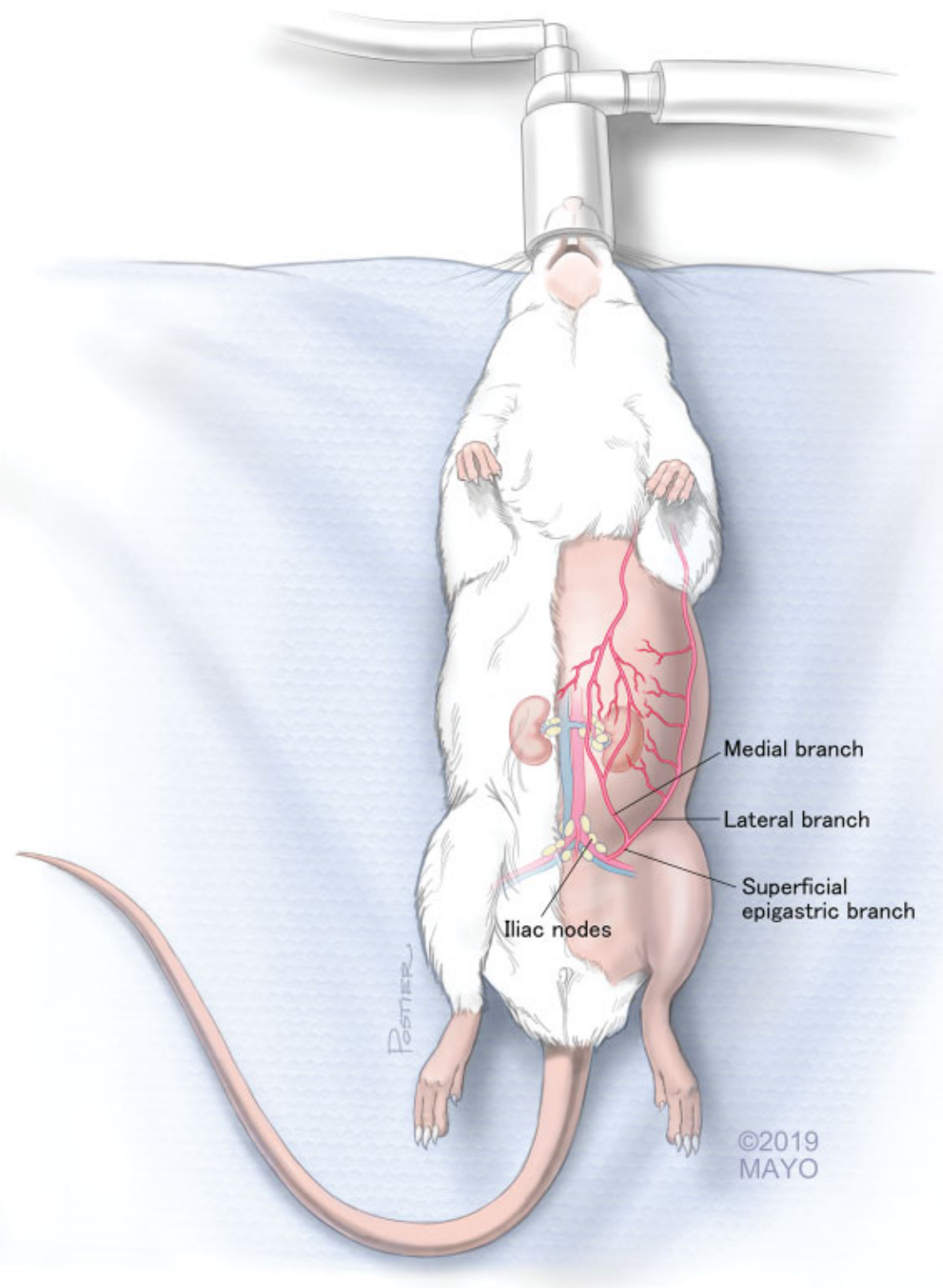

Fig. 1 Schematic drawing of the rat superficial vascular abdominal anatomy. The superficial epigastric artery originates from the femoral artery and divides into two branches to supply the abdominal fascia: the lateral and the medial branches. Close to the bifurcation lie the iliac nodes. (Reproduced with permission of Mayo Foundation for Medical Education and Research. All rights reserved).

Sommerville, NJ) were placed through the SIEF flap (-Fig. 5D). Wounds were closed in layers, with muscle approximated with 5-0 absorbable sutures (5-0 Vicryl Rapide; Ethicon Inc., Sommerville, NJ), and the skin of the leg and the abdomen was closed subcutaneously using the same suture.

\section{Evaluation SIEF Flap}

The viability of the SIEF flap was evaluated at sacrifice by 12 and 16 weeks. This was performed using the milking patency test. ${ }^{28}$ The SIEA was found and the vessel was occluded with forceps distal to the flap. The other forceps was placed just distally to the first. The vessel would be milked a few millimeters away from the flap. Thereafter, the proximal forceps would be released. Rapid filling from proximal to distal would indicate that the artery was not occluded (1); if no filling occurred, the test would be scored a (0). Viability of the flap was also characterized by color of the flap and active bleeding at the edges of the flap.

\section{Immunohistochemistry}

At 12 weeks, immunohistochemical staining of the nerves was obtained to confirm revascularization of the nerve. After sacrifice, the nerve grafts were harvested and fixed in $10 \%$ formalin (Fisher Scientific, $\mathrm{NH}$ ) for 48 hours, transferred to $70 \%$ ethanol, and stored at $4^{\circ} \mathrm{C}$. After embedding in paraffin, serial sections ( $5 \mu \mathrm{m}$ ) were obtained from distal parts of the nerve grafts. These sections were stained with hematoxylin and eosin (H\&E) and primary antibody rabbit antirat CD34 (1:4000; Abcam, Cambridge, MA) to visualize 


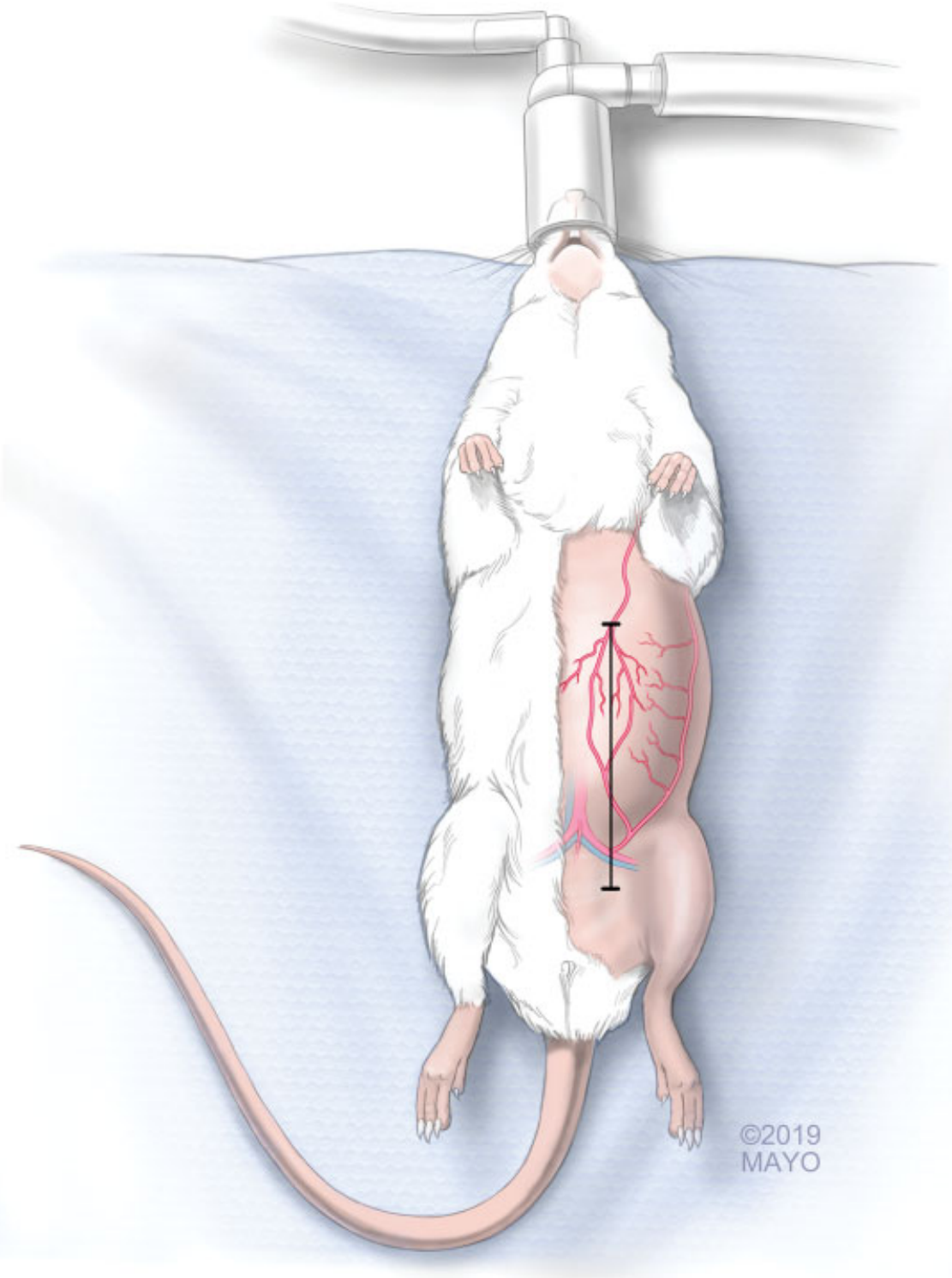

Fig. 2 Schematic drawing of the $4 \mathrm{~cm}$ paramedian incision. This incision allows for harvesting the flap without damaging the SIE vessels or other vessels supplying the abdominal skin. (Reproduced with permission of Mayo Foundation for Medical Education and Research. All rights reserved). SIE, superficial inferior epigastric.

vascularization and fibrosis in the nerve graft. CD34 is a transmembrane phosphoglycoprotein and established as a marker of hematopoietic cell types, including vascular endothelial progenitors and extensively expressed on blood vessels. $^{29}$ Contralateral nerve samples were stained as control. Immunohistochemical digital photographs were taken at $\times 40$ magnification with a microscope (Nikon Eclipse 50i) equipped with a digital camera. Images were qualitatively assessed.

\section{Results}

\section{Evaluation SIEF Flap}

Successful flap transfer was accomplished in all rats. After 12 and 16 weeks, rats were sacrificed and flap viability was investigated. The patency of the artery was checked with the milking patency test at sacrifice and all arteries were patent after 12 and 16 weeks of survival. The flap was well vascularized and demonstrated active bleeding at its margins. The vessels were in line with the nerve graft (-Fig. 6).

No flap necrosis occurred and no infections were seen. Of the 12-week survival rats, lymphedema occurred in two which did not infect or complicate recovery and resolved by itself. In one rat, a small subcutaneous hematoma was seen on the abdominal side at 4 weeks, which did not increase size during follow-up and did not have any impact on the SIEF flap. The 16-week survival rats did not show any complications. The SIEF flap had an acceptable and aesthetic donor site scar without any observable loss of function.

\section{Immunohistochemistry}

To assess the effect of the SIEF flap on nerve allograft samples, nerve samples were stained for $\mathrm{H} \& \mathrm{E}$ and antiCD34. Results of H\&E staining in cross-sections of the nerve 

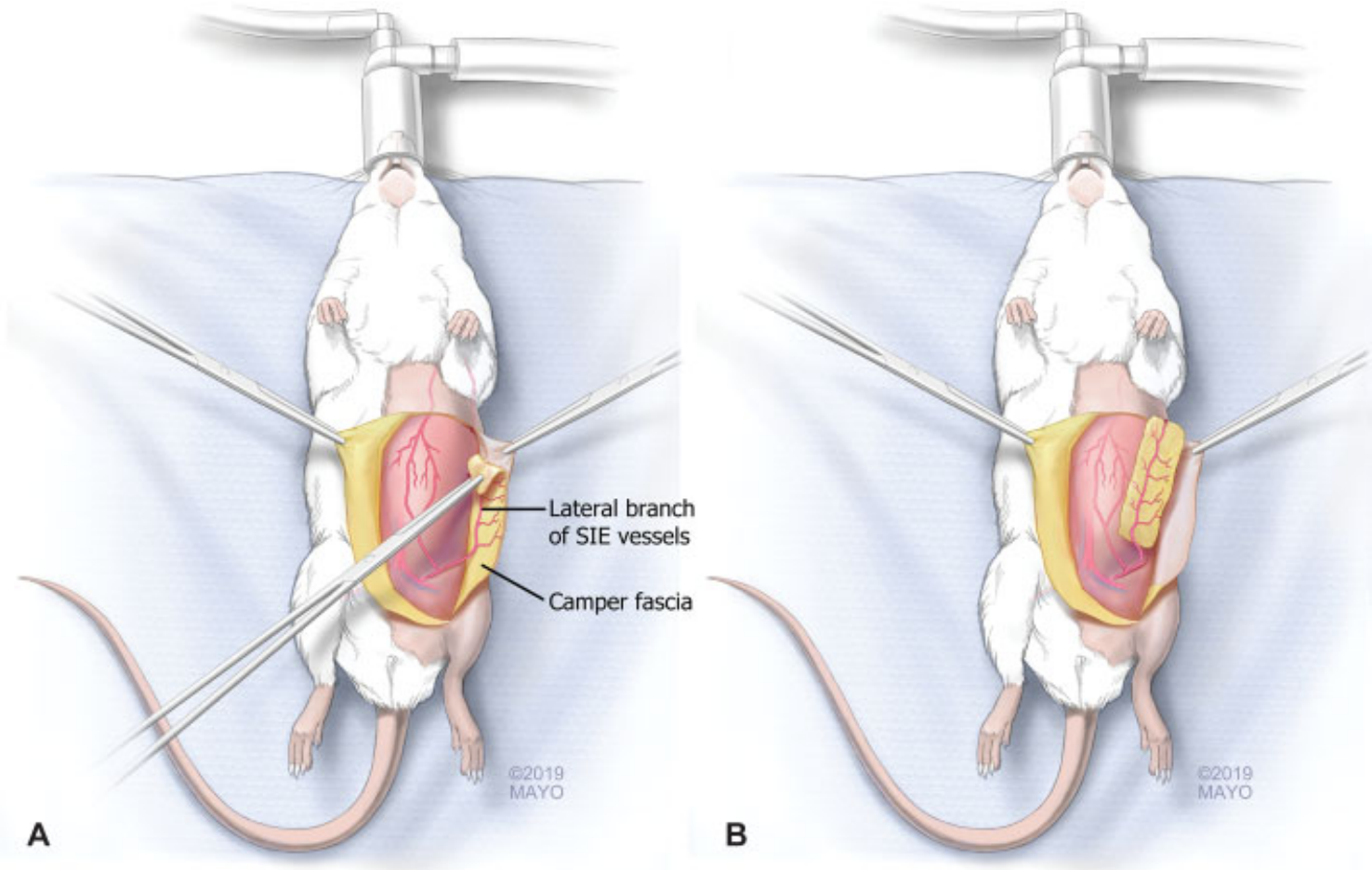

Fig. 3 Schematic drawing of SIEF flap harvest. Depicted is elevating the flap from distal to proximal (A), providing a $4 \times 3$-cm adipofascial flap (B) with lateral branch of the superficial inferior vessels. (Reproduced with permission of Mayo Foundation for Medical Education and Research. All rights reserved). SIEF, superficial inferior epigastric fascia.
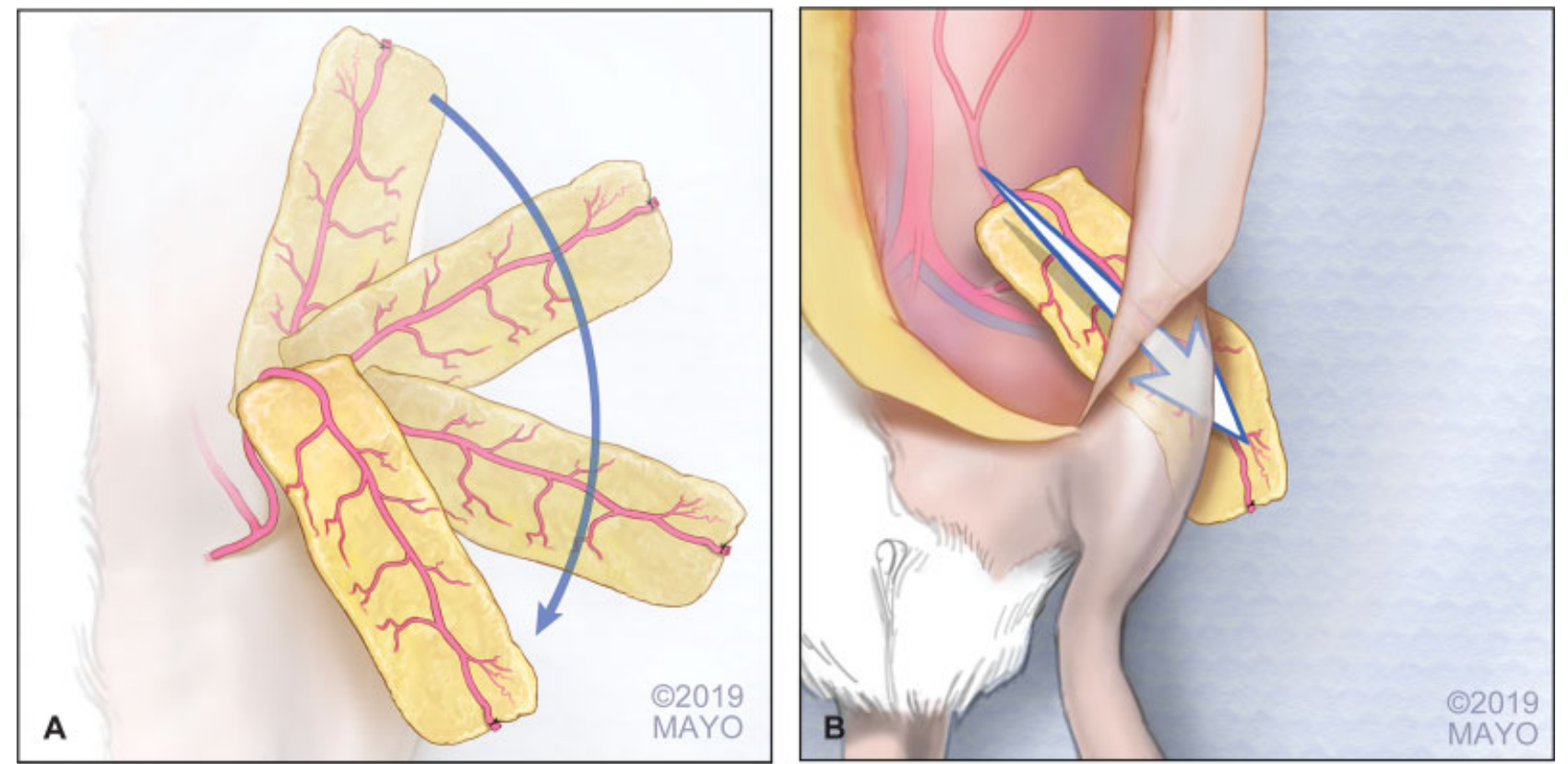

Fig. 4 Schematic drawing of flap rotation (A) and tunneling (B). The vessels were kept ventrally and the flap was tunneled without vascular twisting of the epigastric trunk. (Reproduced with permission of Mayo Foundation for Medical Education and Research. All rights reserved).

showed no infiltration of inflammatory cells in either group at 12 weeks. As can be concluded from the H\&E staining, no fibrosis was seen. In the SIEF group, an increase in vessels and Schwann cell nuclei was evident in the H\&E stained samples. This increase in vessels was consistent with the notable increase of CD34-positive microvessels in nerve grafts that were surgically revascularized at 12 weeks compared with unoperated nerve samples ( - Fig. $\mathbf{7}$ ).

\section{Discussion}

The surgical technique for the rat SIEF flap harvest was described and evaluated. While this flap has been reported previously in a few animal studies, ${ }^{17,19,20}$ long-term viability has not been adequately assessed or determined. Additionally, a succinct and detailed description of this technique in rats has not been illustrated or reported. 

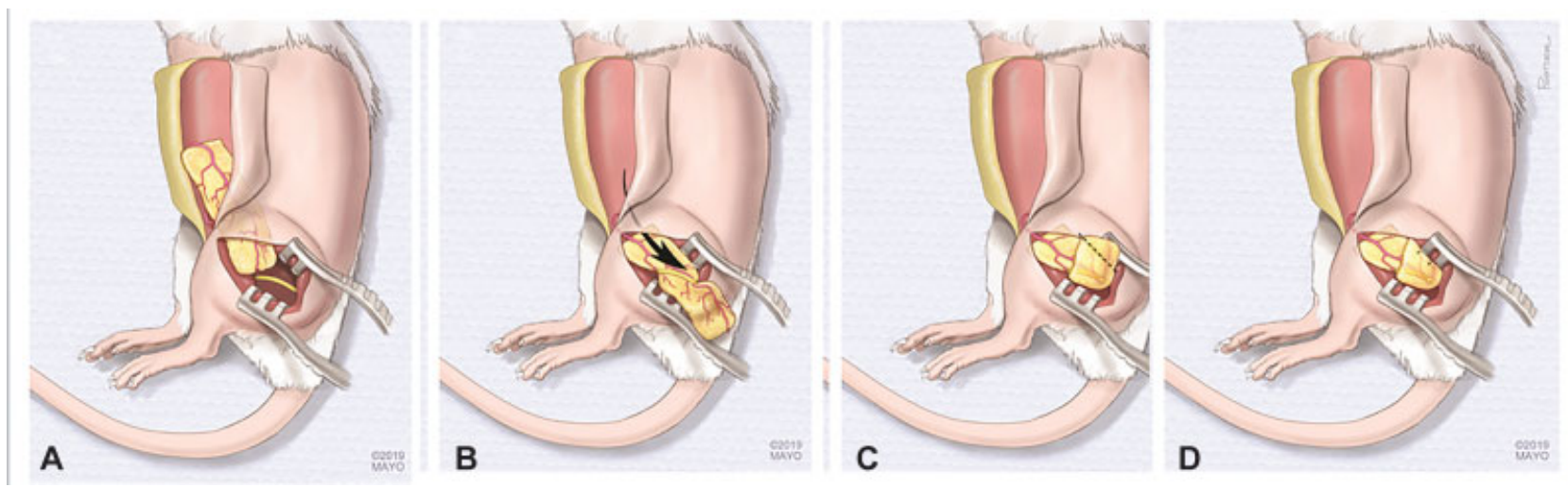

Fig. 5 Schematic drawings of SIEF flap positioning. The SIEF flap was tunneled subcutaneously toward the nerve reconstruction (A) without torsion of the pedicle and wrapped around the nerve graft reaching both anastomoses (B). The flap edges were trimmed (C) and two 10-0 nylon sutures were placed to secure the position of the SIEF flap (D). (Reproduced with permission of Mayo Foundation for Medical Education and Research. All rights reserved). SIEF, superficial inferior epigastric fascia.

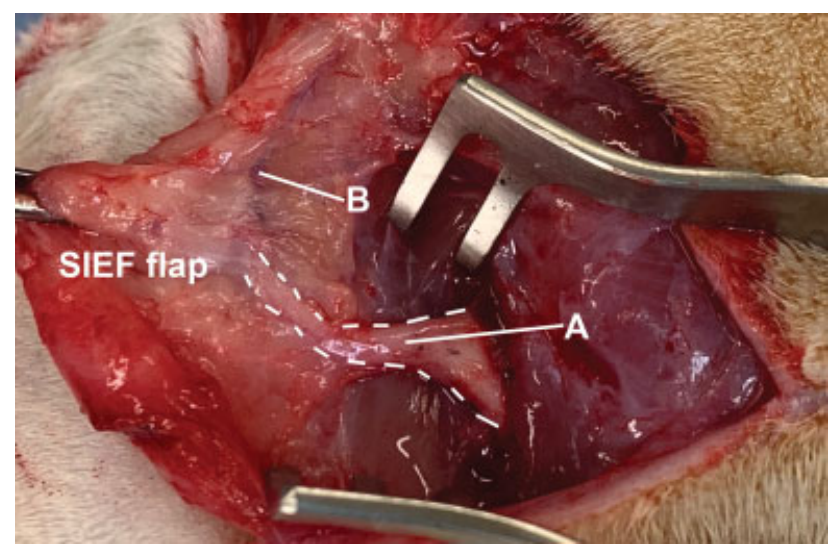

Fig. 6 Relation SIE vessels and nerve after 16 weeks. The white dashed line surrounds the nerve allograft $(A)$. Depicted is the close relationship between the nerve allograft (A) and the SIE vessels (B) after 16 weeks of survival. Also, flap viability could clearly be seen. SIE, superficial inferior epigastric.

The main findings of this study were that the SIEF flap is an easy flap to raise and remains viable in all rats after either a 12 or 16 -week survival period. Complications included two lymphoceles and one hematoma acutely, but no long-term consequences at 12 and 16 weeks.

The flap demonstrated to have $100 \%$ success rates after elevation without flap failure or necrosis at the donor site. One major advantage is that the SIE vessels of the rat are approximately $0.5 \mathrm{~mm}$ in diameter, ${ }^{30}$ which categorizes it as relatively large and makes them to be easily dissected under loupe magnification. By only including the lateral branch, necrosis at the donor site is prevented. This flap design can be applied to other rat strains as well as rats of different sizes as the anatomical branches are easily recognized. The pedicled flap eliminates the need for microvascular anastomosis and minimizes flap failures secondary to surgical techniques. This pedicled flap allows for a technically simple elevation without intramuscular dissection and a relatively short operation time. An additional benefit is that the transplanted adipofascial tissue can improve blood flow in adjacent tissues such as bone, nerve, and muscles and be a readily applied pedicle flap for studies on vascularization. ${ }^{20,31}$ The inclusion of adipofascial tissue in the flap decreases intravascular resistance of the bundle, resulting in improved blood flow in the flap which decreases the risk of thrombosis. ${ }^{20,31}$

Immunohistochemical qualitative analysis of the nerve samples confirms the increase in vascularity in the SIEF group (vascularized flap wrapped around the processed nerve allograft) in both $\mathrm{H} \& \mathrm{E}$ and anti CD-34 sections at 12 weeks. Vasculature is known to play a crucial role in supporting nerve regeneration following injury. ${ }^{32}$ A lack of blood supply could lead to nerve hypoxia and damage, leading to nerve fibrosis. ${ }^{33,34}$ At time of a nerve injury, Wallerian degeneration is activated causing Schwann cell proliferation distal to the nerve injury. ${ }^{35,36}$ This process causes blood vessels to precede Schwann cell migration and to stimulate axonal extension, describing an important interaction between Schwann cells and blood vessels. ${ }^{34,37}$ Schwann cells are known to produce neurotrophic factors to support neurite outgrowth. ${ }^{38}$ After nerve injury, these cells and their secreted neuro-supportive factors enhance axonal growth. ${ }^{39}$ Although comparison of nerve allograft in a wellvascularized bed to the contralateral unoperated nerve is not an adequate comparison of nerve tissue, the increase of vessels and Schwann cell nuclei in the nerve allografts confirm the relationship between blood supply and nerve regeneration and suggest that addition of a well-vascularized bed to the nerve area may enhance nerve regeneration. This study describes a pedicled adipofascial flap model in rats and validates its use in future investigations in the rat sciatic nerve model.

\section{Conclusion}

This study demonstrated a total success rate of SIEF flap viability without necrosis at 12 and 16 weeks, providing evidence that this flap is durable and can be used for future studies in a rat model. We recommend this simple technique to add vascularization to various tissues in the lower abdomen, genital area, thigh, and upper limb of the rat. 


\section{Control}
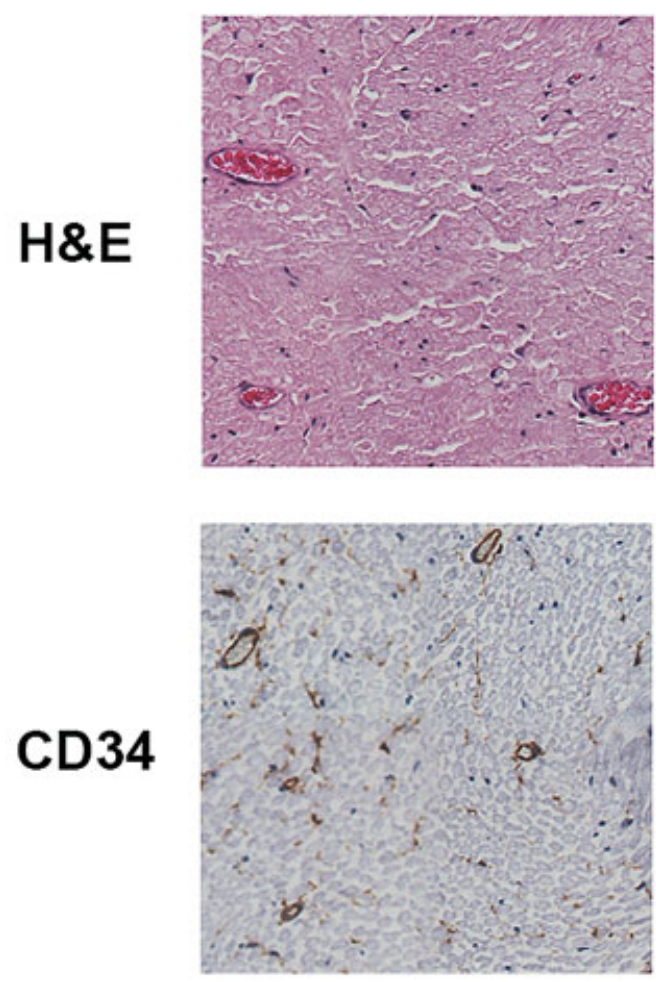

SIEF
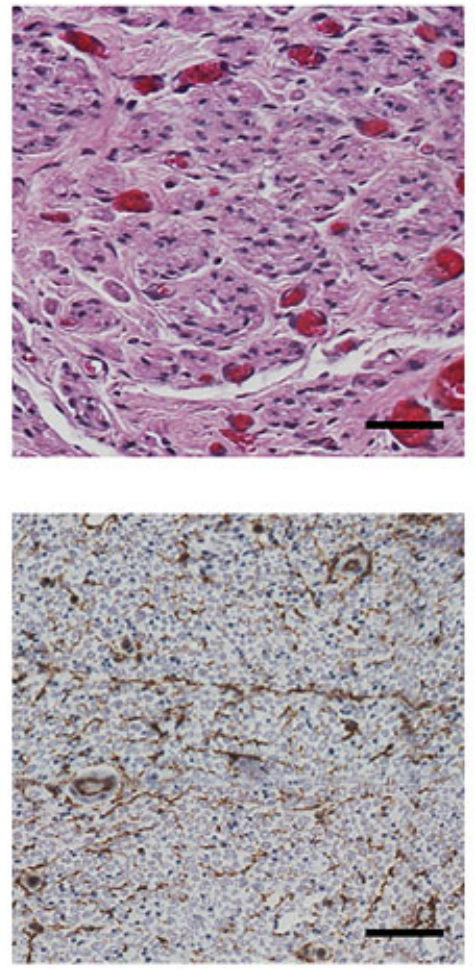

Fig. 7 Immunohistochemical digital photographs of nerve samples. Representative images of H\&E staining in control (contralateral unoperated nerve) and SIEF (vascularized flap wrapped around the processed nerve allograft) samples at 12 weeks. Purple nuclei denote the Schwann cell nuclei. Digital photographs were taken at $\times 40$ magnification. Scale bars, $200 \mu \mathrm{m}$. H\&E, hematoxylin and eosin; SIEF, superficial inferior epigastric fascia.

Note

The study was performed at Mayo Clinic, Rochester, United States. The content is solely the responsibility of the authors and does not necessarily represent the official views of the National Institutes of Health.

\section{Funding}

Research reported in this publication was supported by the National Institute of Neurological Disorders and Stroke of the National Institutes of Health under award number R01NS102360.

\section{Conflict of Interest}

A.Y.S. reports grants from National Institutes of Health during the conduct of the study; all the other authors report no conflict of interest.

\section{Acknowledgment}

Artwork of - Figs. 1 to $\mathbf{5}$ was created by Jim Postier, Mayo Clinic, Rochester, MN, United States.

\section{References}

1 Taylor GI, Ham FJ. The free vascularized nerve graft. A further experimental and clinical application of microvascular techniques. Plast Reconstr Surg 1976;57(04):413-426

2 Townsend PL, Taylor GI. Vascularised nerve grafts using composite arterialised neuro-venous systems. Br J Plast Surg 1984;37(01):1-17
3 Rose EH, Kowalski TA, Norris MS. The reversed venous arterialized nerve graft in digital nerve reconstruction across scarred beds. Plast Reconstr Surg 1989;83(04):593-604

4 Doi K, Kuwata N, Kawakami F, Tamaru K, Kawai S. The free vascularized sural nerve graft. Microsurgery 1984;5(04):175-184

5 Doi K, Kuwata N, Sakai K, Tamaru K, Kawai S. A reliable technique of free vascularized sural nerve grafting and preliminary results of clinical applications. J Hand Surg Am 1987;12(5 Pt 1):677-684

6 D’Arpa S. Vascularized nerve "grafts": just a graft or a worthwhile procedure? Plast Aesthet Res 2016;2:183-192

7 Strauch B, Murray DE. Transfer of composite graft with immediate suture anastomosis of its vascular pedicle measuring less than $1 \mathrm{~mm}$. in external diameter using microsurgical techniques. Plast Reconstr Surg 1967;40(04):325-329

8 Padubidri AN, Browne E Jr. Modification in flap design of the epigastric artery flap in rats-a new experimental flap model. Ann Plast Surg 1997;39(05):500-504

9 Freeman TJ, Cohen JI. The ventral 'L' island flap. A refined model for skin flap research. Arch Otolaryngol Head Neck Surg 1990;116 (02):189-190

10 Tsuzuki K, Yanai A, Tange I, Bandoh Y. The influence of congestion and ischemia on survival of an experimental vascular pedicle island flap. Plast Reconstr Surg 1989;84(05):789-793

11 Takayanagi S, Ota C, Kusumoto K, Hosomi Y. Experimental evaluation of vascular pedicle in island flaps. Br J Plast Surg 1986;39(03):352-355

12 Zuker RM, Harii K. A random pattern flap borne on an axial pattern flap: experimental study in rats. Br J Plast Surg 1978;31 (04):286-289

13 Hsu CE, Shyu VB, Wen CJ, Wei FC, Huang XT, Cheng HY. The rat groin flap model redesigned for evaluating treatment effects on ischemia-reperfusion injury. J Surg Res 2018;222:160-166 
14 Ylmaz KB, Gurunluoglu R, Bayramiçli M. Flap survival after previous vascular pedicle division and preexisting scar formation at the pedicle site: an experimental study. Ann Plast Surg 2014;73(04): 434-440

15 Demirseren ME, Yenidunya MO, Yenidunya S. Island rat groin flaps with twisted pedicles. Plast Reconstr Surg 2004;114(05):1190-1194

16 Tark KC, Khouri RK, Shin KS, Shaw WW. The fasciovascular pedicle for revascularization of other tissues. Ann Plast Surg 1991;26(02): 149-155

17 Dunn RM, Mancoll J. Flap models in the rat: a review and reappraisal. Plast Reconstr Surg 1992;90(02):319-328

18 O'Sullivan KL, Pap SA, Megerian CA, et al. Improved axon diameter and myelin sheath thickness in facial nerve cable grafts wrapped in temporoparietal fascial flaps. Ann Plast Surg 1998;40(05):478-485

19 Valdatta L, Reguzzoni M, Buoro M, et al. Neurovenous superficial inferior epigastric flaps in rats. Minerva Chir 2003;58(03):361-368

20 Giessler GA, Friedrich PF, Shin RH, Bishop AT. The superficial inferior epigastric artery fascia flap in the rabbit. Microsurgery 2007;27(06):560-564

21 Giusti G, Willems WF, Kremer T, Friedrich PF, Bishop AT, Shin AY. Return of motor function after segmental nerve loss in a rat model: comparison of autogenous nerve graft, collagen conduit, and processed allograft (AxoGen). J Bone Joint Surg Am 2012;94 (05):410-417

22 Shin RH, Vathana T, Giessler GA, Friedrich PF, Bishop AT, Shin AY. Isometric tetanic force measurement method of the tibialis anterior in the rat. Microsurgery 2008;28(06):452-457

23 Hundepool CA, Nijhuis TH, Rbia N, Bulstra LF, Selles RW, Hovius SE. Noninvasive ultrasound of the tibial muscle for longitudinal analysis of nerve regeneration in rats. Plast Reconstr Surg 2015; 136(05):633e-639e

24 Hundepool CA, Nijhuis TH, Kotsougiani D, Friedrich PF, Bishop AT, Shin AY. Optimizing decellularization techniques to create a new nerve allograft: an in vitro study using rodent nerve segments. Neurosurg Focus 2017;42(03):E4

25 Hudson TW, Zawko S, Deister C, et al. Optimized acellular nerve graft is immunologically tolerated and supports regeneration. Tissue Eng 2004;10(11-12):1641-1651
26 Kumta S, Yip K, Roy N, Lee SK, Leung PC. Revascularisation of bone allografts following vascular bundle implantation: an experimental study in rats. Arch Orthop Trauma Surg 1996; 115(3-4):206-210

27 Petry JJ, Wortham KA. The anatomy of the epigastric flap in the experimental rat. Plast Reconstr Surg 1984;74(03):410-413

28 Hayhurst JW, O'Brien BM. An experimental study of microvascular technique, patency rates and related factors. Br J Plast Surg 1975;28(02):128-132

29 Fina L, Molgaard HV, Robertson D, et al. Expression of the CD34 gene in vascular endothelial cells. Blood 1990;75(12):2417-2426

30 Cubitt J, Pennington T, Wang C, Allen R, Bishop A, Sharland A. Reliable and reproducible murine models for commonly used abdominal plastic surgical flaps. J Reconstr Microsurg 2012;28 (03):161-166

31 Sasmor MT, Reus WF, Straker DJ, Colen LB. Vascular resistance considerations in free-tissue transfer. J Reconstr Microsurg 1992; 8(03): 195-200

32 Terzis JK, Skoulis TG, Soucacos PN. Vascularized nerve grafts. A review. Int Angiol 1995;14(03):264-277

33 Muangsanit P, Shipley RJ, Phillips JB. Vascularization Strategies for Peripheral Nerve Tissue Engineering. Anat Rec (Hoboken) 2018; 301(10):1657-1667

34 Hobson MI, Brown R, Green CJ, Terenghi G. Inter-relationships between angiogenesis and nerve regeneration: a histochemical study. Br J Plast Surg 1997;50(02):125-131

35 Stoll G, Müller HW. Nerve injury, axonal degeneration and neural regeneration: basic insights. Brain Pathol 1999;9(02):313-325

36 Jessen KR, Mirsky R. The repair Schwann cell and its function in regenerating nerves. J Physiol 2016;594(13):3521-3531

37 Hobson MI, Green CJ, Terenghi G. VEGF enhances intraneural angiogenesis and improves nerve regeneration after axotomy. J Anat 2000;197(Pt 4):591-605

38 Bunge RP. The role of the Schwann cell in trophic support and regeneration. J Neurol 1994;242(01, Suppl 1):S19-S21

39 Koppes AN, Nordberg AL, Paolillo GM, et al. Electrical stimulation of schwann cells promotes sustained increases in neurite outgrowth. Tissue Eng Part A 2014;20(3-4):494-506 